\title{
Lead Nanowires for Microaccumulators Obtained Through Indirect Electrochemical Template Deposition
}

\author{
R. Inguanta, ${ }^{*}$ E. Rinaldo, S. Piazza, ${ }^{\mathrm{z}}$ and C. Sunseri ${ }^{* *}$ \\ Dipartimento di Ingegneria Chimica dei Processi e dei Materiali, Università di Palermo, Viale delle \\ Scienze, 90128 Palermo, Italy
}

\begin{abstract}
Metallic lead nanowires were deposited within pores of commercial anodic alumina membranes having an average pore diameter of $210 \mathrm{~nm}$. "Direct" electrodeposition was attempted from $0.1 \mathrm{M} \mathrm{Pb}\left(\mathrm{NO}_{3}\right)_{2}$ aqueous solution with a variable concentration of $\mathrm{H}_{3} \mathrm{BO}_{3}$ as a chelating agent, but it gave unsatisfactory results. An "indirect" two-step deposition procedure was then adopted, consisting of the anodic electrodeposition of $\alpha-\mathrm{PbO}_{2}$ nanowires, followed by their in situ reduction to metallic lead. Both these processes occurred at a high rate so that the indirect method led to a complete template pore filling with pure polycrystalline $\mathrm{Pb}$ in short times and with a high current efficiency.

(C) 2009 The Electrochemical Society. [DOI: 10.1149/1.3246944] All rights reserved.
\end{abstract}

Manuscript submitted July 29, 2009; revised manuscript received September 16, 2009. Published October 16, 2009.

Miniaturization is a key issue in the frame of actual technology. The control of materials and devices at a very small scale leads to better performances at a reduced cost, and it opens the way for applications in different fields of engineering, biology, and medicine. ${ }^{1,2}$ This holds for the field of energy storage, too, where the fabrication of micro- or nanoaccumulator arrays with an extremely high interfacial area is a challenging goal. ${ }^{3}$ Despite environmental problems and the relatively low specific energy storage in comparison with other galvanic generators, lead acid batteries are still extensively used in the field of energy accumulation, owing to a wellknown and reliable technology. ${ }^{4}$, Thus, it is of high technological interest to develop procedures for fabricating these devices at a micrometer scale or less.

In a recent work, ${ }^{6}$ we have grown ordered $\mathrm{PbO}_{2}$ nanowire (NW) arrays having various crystalline structures by electrodeposition from suitable electrolytes into the pores of anodic alumina membrane (AAM) templates. Similar structures were deposited by Perret et al. ${ }^{7}$ from a nitrate bath. They also checked the reactivity of $\mathrm{PbO}_{2}$ NWs as a function of the number of cycles performing cyclic voltammetry between 0.5 and $2 \mathrm{~V}$ vs saturated calomel electrode (SCE) in a sulfuric acid electrolyte.

The fabrication of metallic $\mathrm{Pb}$ NWs is the second step to accomplish the final goal of building lead acid microbatteries. However, this issue presents some difficulty, owing to complications arising from the electrodeposition process of lead. Despite favorable thermodynamics and high overvoltage for hydrogen evolution, nucleation of a solid $\mathrm{Pb}$ phase from a bath containing $\mathrm{Pb}^{2+}$ ions is often complicated by the formation of dendrites, ramifications, nodules, or voids. ${ }^{8,9}$ Usually, all these effects hinder the formation of a uniform and compact metal deposit; consequently, several additives having a leveling action are used in the industrial $\mathrm{Pb}$ electrodeposition processes. ${ }^{10}$ The above complications are amplified in $\mathrm{Pb}$ nanostructures where a regular geometry controlled at a submicrometer scale is required. Besides, the most common electrolyte used to obtain a compact and smooth lead deposit $\left(\mathrm{HBF}_{4}\right)$ is not compatible with the chemical stability of our template because alumina rapidly dissolves, owing to the reaction with fluoride ions leading to the formation of alumino-fluoro complexes. ${ }^{11}$

Here, we report the preliminary results of an investigation in which we first faced the problem of trying a "direct" cathodic electrodeposition of lead from baths having a suitable composition. The unsatisfactory results, in terms of geometrical regularity and rate of deposition, forced us to experience an alternative way to obtain metallic $\mathrm{Pb}$ NWs within template pores through an "indirect" method.

\footnotetext{
* Electrochemical Society Student Member.

** Electrochemical Society Active Member.

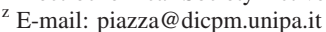

\section{Experimental}

Commercial AAM templates (Whatman, Anodisc 47, U.K.) having a mean pore diameter of $210 \mathrm{~nm}$ and an initial thickness of about $60 \mu \mathrm{m}$ were cut into pieces of about $1 \mathrm{~cm}^{2}$ surface area, sputtered on one side with gold, ${ }^{12,13}$ and glued onto an aluminum support through a conductive glue. The active sample area was delimited by an insulating lacquer.

Direct electrodepositions were performed in a three-electrode cell having a graphite counter electrode, and a standard calomel reference electrode connected to the cell through a salt bridge. The electrolyte was an aqueous solution of $0.1 \mathrm{M} \mathrm{Pb}\left(\mathrm{NO}_{3}\right)_{2}$ with a variable concentration of $\mathrm{H}_{3} \mathrm{BO}_{3}(\mathrm{pH} 3.4-4)$. The effect of $\mathrm{pH}$ and stirring, as well as of the deposition mode, was investigated. This preliminary study was also carried out for massive lead film deposition on graphite electrodes, and it will be detailed in a future work. ${ }^{14}$ The indirect electrodeposition consisted of two steps: $(i)$ growth of $\alpha-\mathrm{PbO}_{2} \mathrm{NWs}$ within membrane pores according to the procedure reported in Ref. 6 and (ii) in situ reduction of lead oxide NWs to metallic $\mathrm{Pb}$. This second step was potentiostatically (at -1 $\mathrm{V} / \mathrm{SCE}$ ) and galvanostatically carried out in an aqueous $5 \mathrm{M} \mathrm{H}_{2} \mathrm{SO}_{4}$ or $1 \mathrm{M} \mathrm{Na}_{2} \mathrm{SO}_{4}$ solution.

In all cases, the current vs time or the potential vs time curves were monitored and acquired through an analogic interface controlled by homemade programs using a LabVIEW 7 software.

Deposits were characterized by scanning electrode microscopy (SEM) using an FEI FEG-ESEM (QUANTA 200 model) equipped with an energy disperse spectroscopy (EDS) detector and X-ray diffraction (XRD) analysis using a Philips (PW 1130) or an ItalStructures (APD2000) diffractometer, both having $\mathrm{Cu} \mathrm{K} \alpha$ radiation $(\lambda$ $=0.154 \mathrm{~nm})$ as the source, with a step of $0.02^{\circ}$ and a measuring time of $0.5 \mathrm{~s}$ for each step. XRD peaks were identified by comparing with the International Center for Diffraction Data database. ${ }^{13}$ $\alpha-\mathrm{PbO}_{2} \mathrm{NWs}$ were also characterized by Raman spectroscopy. ${ }^{6}$

\section{Results and Discussion}

Direct depositions. - Table I reports the experimental conditions for the direct electrodeposition of metallic $\mathrm{Pb}$ NWs into AAM templates. In the potentiostatic depositions, all carried out at $-0.5 \mathrm{~V}$ (SCE) after a short period (a few seconds), the cathodic current increased with time very rapidly during the first few minutes and then much more gradually. However, the measured current was influenced by the solution $\mathrm{pH}$ and by stirring. At the end of the experiments, the $\mathrm{pH}$ of the electrolytic solution was found slightly lower with respect to the initial value (from 2.9 to 3.3), likely due to the acidification that occurred in the one-compartment cell by the anodic counter-reaction

$$
\mathrm{Pb}^{2+}+2 \mathrm{H}_{2} \mathrm{O}=\mathrm{PbO}_{2}+4 \mathrm{H}^{+}+2 \mathrm{e}^{-}
$$

XRD patterns indicated a formation of polycrystalline pure $\mathrm{Pb}$ deposits with preferential orientations along the (111) or the (220) 


\begin{tabular}{|c|c|c|c|c|}
\hline Sample & Solution & $\begin{array}{c}\text { Agitation } \\
\text { (rpm) }\end{array}$ & $\begin{array}{l}\text { Electrodeposition } \\
\text { condition }\end{array}$ & $\begin{array}{c}\text { Time } \\
(\mathrm{h})\end{array}$ \\
\hline a & $0.1 \mathrm{M} \mathrm{Pb}\left(\mathrm{NO}_{3}\right)_{2}+0.2 \mathrm{M} \mathrm{H}_{3} \mathrm{BO}_{3}$ with $\mathrm{pH} 4$ & - & $-0.5 \mathrm{~V}(\mathrm{SCE})$ & 0.5 \\
\hline $\mathrm{b}$ & $0.1 \mathrm{M} \mathrm{Pb}\left(\mathrm{NO}_{3}\right)_{2}+0.2 \mathrm{M} \mathrm{H}_{3} \mathrm{BO}_{3}$ with pH 4 & 350 & $-0.5 \mathrm{~V}(\mathrm{SCE})$ & 1 \\
\hline $\mathrm{c}$ & $0.1 \mathrm{M} \mathrm{Pb}\left(\mathrm{NO}_{3}\right)_{2}+$ saturated $\mathrm{H}_{3} \mathrm{BO}_{3}$ with $\mathrm{pH} 3.6$ & - & $-0.5 \mathrm{~V}(\mathrm{SCE})$ & 1 \\
\hline $\mathrm{d}$ & $0.1 \mathrm{M} \mathrm{Pb}\left(\mathrm{NO}_{3}\right)_{2}+$ saturated $\mathrm{H}_{3} \mathrm{BO}_{3}$ with $\mathrm{pH} 3.6$ & - & $-5 \mathrm{~mA} \mathrm{~cm}^{-2}$ & 1 \\
\hline $\mathrm{e}$ & $0.1 \mathrm{M} \mathrm{Pb}\left(\mathrm{NO}_{3}\right)_{2}+$ saturated $\mathrm{H}_{3} \mathrm{BO}_{3}$ with $\mathrm{pH} 3.6$ & - & $-0.5 \mathrm{~V}(\mathrm{SCE})$ & 3 \\
\hline $\mathrm{f}$ & $0.1 \mathrm{M} \mathrm{Pb}\left(\mathrm{NO}_{3}\right)_{2}+$ saturated $\mathrm{H}_{3} \mathrm{BO}_{3}$ with $\mathrm{pH} 3.6$ & - & $-5 \mathrm{~mA} \mathrm{~cm}^{-2}$ & 3 \\
\hline
\end{tabular}

plane agreeing with analogous experiments performed on massive films. ${ }^{14}$ These results have shown that the addition of boric acid up to saturation favors the growth of compact deposits, but it noticeably slowed down the deposition process without totally hindering dendrite formation. In nanostructure deposition, SEM analysis revealed a sporadic filling of template pores (see Fig. 1a) with NWs having a limited and nonuniform length. Similar findings were reported by Chi. ${ }^{16}$ Also for template deposition, an excess of chelating agent $\left(\mathrm{H}_{3} \mathrm{BO}_{3}\right)$ in the bath improved pore filling, but it was impossible to
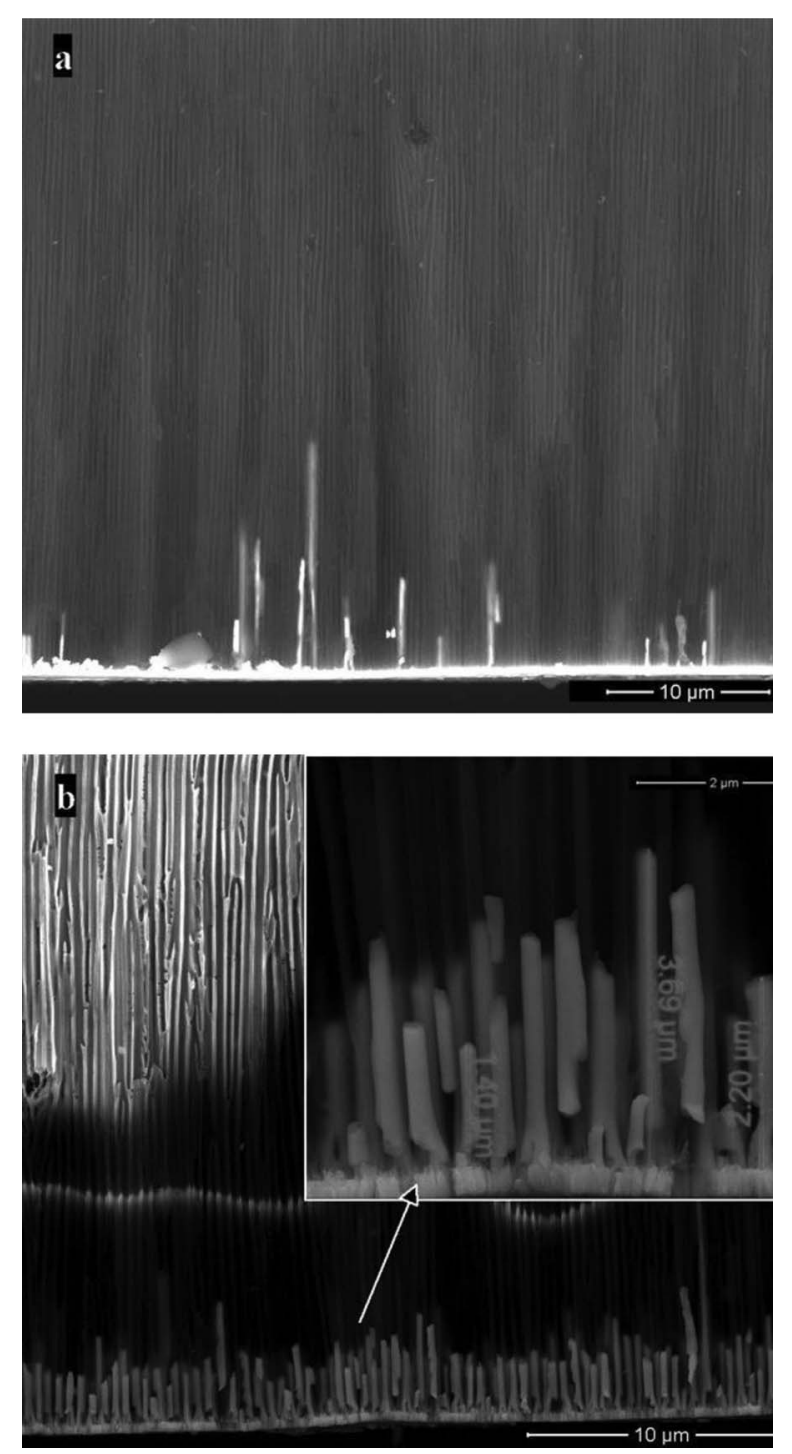

Figure 1. Cross-sectional views of $\mathrm{Pb} \mathrm{NWs}$ deposited in AAM templates from a $\mathrm{Pb}\left(\mathrm{NO}_{3}\right)_{2}$ bath: (a) Sample a of Table I and (b) sample d of Table I. Inset: Enlarged view of sample d. rapidly fill all channels with NWs of uniform length. In previous works, ${ }^{17-19}$ lead NWs were grown in conditions analogous to ours even if a comparison with our findings is rather difficult because those papers do not show section views of the deposit; therefore, it is impossible to compare pore filling and NW length uniformity.

Better results were obtained by performing galvanostatic cathodic deposition (experiment $d$ in Table I). In this case, a more uniform NW length and better filling of pores were observed, as shown in Fig. 1b. The growth curve for this experiment displays a negative potential peak reached after $\sim 100 \mathrm{~s}$, after which the electrode potential rises fast up to $-0.55 \mathrm{~V}$, and then it continues to increase slowly up to $1 \mathrm{~h}$ deposition, corresponding to a circulated charge of $18 \mathrm{C} \mathrm{cm}^{-2}$. This increase in the electrode potential is likely due to metallic $\mathrm{Pb}$ deposition within the template pores, with a consequent increase in electrical conductance. EDS analysis confirmed that also in this case, NWs consisted of pure $\mathrm{Pb}$, while XRD patterns showed a polycrystalline structure without preferential orientations. Also in this case, the NW length was far from uniform, and the growth rate was quite slow.

In conclusion, lead NWs were obtained by cathodic deposition in both potentiostatic and galvanostatic conditions, but the quality of deposit was unsatisfactory in terms of pore filling and NW length uniformity even in the presence of boric acid in the electrolyte. This behavior can be due to the difficulty in obtaining a compact deposit of lead from baths different from those containing tetrafluoboric acid. Baths leading to the preferential growth of dendritic structures probably favor the growth of NWs inside the most electrochemical active channels, according to the description reported in our previous work. ${ }^{20}$

Indirect depositions. - To rapidly obtain lead NWs of uniform length and to fill all channels of the alumina template, we have exploited an alternative procedure consisting of two separate steps: In the first step, we have deposited anodic $\alpha-\mathrm{PbO}_{2} \mathrm{NWs}$ into template pores according to the method described in our previous work. ${ }^{6}$ For this aim, a potentiostatic deposition at $+1.5 \mathrm{~V}$ (SCE) was performed from a stirred solution of $0.2 \mathrm{M}$ lead acetate at $T$ $=60^{\circ} \mathrm{C}$. A complete filling of pores was achieved, whose length was uniform and increased with the deposition time in a slightly sublinear fashion; after less than half an hour, membrane pores were completely filled. In agreement with our previous work, ${ }^{6}$ XRD and Raman analyses confirmed that the anodically grown NWs consisted of pure polycrystalline $\alpha-\mathrm{PbO}_{2}$ with a preferential orientation along the (200) plane.

The second step of this procedure consists of the complete reduction of the $\alpha-\mathrm{PbO}_{2} \mathrm{NWs}$ to metallic $\mathrm{Pb}$ within the membrane pores. The reduction process was first tested starting from $\alpha-\mathrm{PbO}_{2}$ thin films deposited onto a graphite support. Here, we report only the main results of this preliminary investigation; details will be given in a future work. ${ }^{14}$ Galvanostatic (at different current densities) and potentiostatic (at $-1 \mathrm{~V} / \mathrm{SCE}$ ) reductions were carried out mainly in a $5 \mathrm{M} \mathrm{H}_{2} \mathrm{SO}_{4}$ solution.

1. In both cases, the reduction process occurred with a faradaic efficiency of $100 \%$ and led to a complete conversion of the oxide film to metallic lead. 


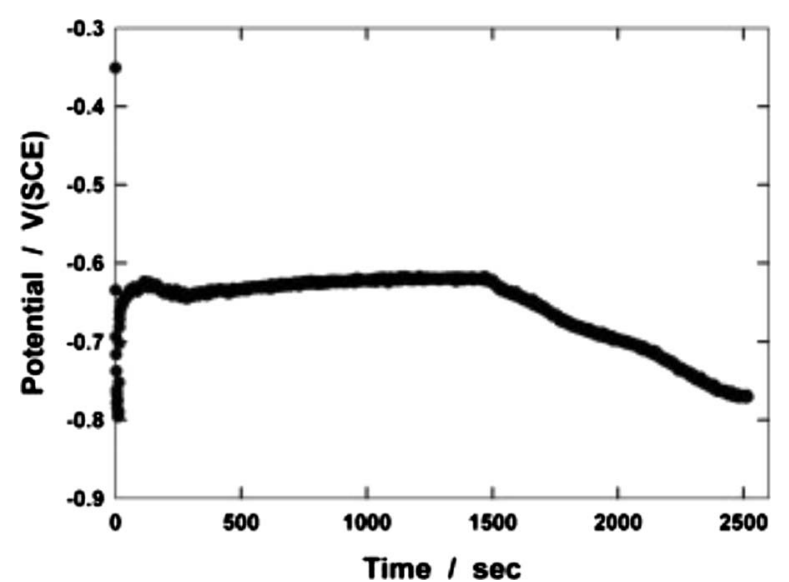

Figure 2. Potential vs time curve during the amperostatic reduction of $\mathrm{PbO}_{2}$ NWs in $5 \mathrm{M} \mathrm{H}_{2} \mathrm{SO}_{4}$ solution at $10 \mathrm{~mA} / \mathrm{cm}^{2}$.

2. A sharp change in the potential-time (galvanostatic reduction) or in the current-time (potentiostatic reduction) curves marked the complete conversion of $\alpha-\mathrm{PbO}_{2}$ to metallic lead, as also confirmed by a sudden and vigorous evolution of hydrogen gas bubbles.

3. After a complete reduction, the films were characterized, and they consisted of pure polycrystalline metallic lead. SEM analysis revealed the presence of cracks on their surface, originating from the volume reduction following the conversion of the oxide into a metallic phase.

However, we met specific difficulties when applying this procedure to the lead dioxide NWs grown within the alumina template. First attempts led to membrane rupture, often preceded by an abundant gas evolution at the corners separating the membrane and the insulating lacquer. We realized these ruptures originating from two effects. The first one is a scarce stability of AAM in the concentrated sulfuric acid solution. In dedicated experiments, we have detected membrane weight losses of 6 and 32\% during immersions lasting for 1 and $9 \mathrm{~h}$, respectively. Owing to this dissolution process, AAM became fragile after a prolonged immersion in the $5 \mathrm{M} \mathrm{H}_{2} \mathrm{SO}_{4}$ electrolyte. The second effect is due to $\mathrm{H}_{2}$ gas evolution on the gold sputtered at the pore bottom. Even a modest peeling of solution gives rise to this process, greatly favored by the low overvoltage for $\mathrm{H}^{+}$reduction. This phenomenon leads to bubble formation beneath the membrane and sealing, causing the membrane to detach from the support.

These observations pushed us to improve the sealing quality. Moreover, galvanostatic reduction can be performed efficiently at $10 \mathrm{~mA} / \mathrm{cm}^{2}$, which represents the best compromise between two opposite needs: to avoid membrane rupture caused by the hydrogen evolution parasitic reaction [higher current densities (cd's)], to minimize the reduction time, and to limit the membrane damage. The potential-time curve relative to this experiment is reported in Fig. 2. After an initial transient, the electrode potential remains almost constant (at $-0.62 \mathrm{~V} / \mathrm{SCE}$ ) for about $25 \mathrm{~min}$, after which it gradually decreases toward more negative values. Such a decrease is likely due to the gradual formation of hydrogen bubbles on NWs partially screening their surface. Thus, different from thin films, $\mathrm{PbO}_{2} \mathrm{NW}$ reduction occurs with a current efficiency of $<1$. Anyway, the process is rapid enough; after about $40 \mathrm{~min}$, reduction is completed at this cd, as revealed by XRD analysis (see below). The time for the complete reduction of the oxide NWs and the shape of the potentialtime curves change with the cd; at $5 \mathrm{~mA} / \mathrm{cm}^{2}$, the potential remained constant (at about $-0.6 \mathrm{~V} / \mathrm{SCE}$ ) for the overall process duration, which lasted for more than $2 \mathrm{~h}$, while at $50 \mathrm{~mA} / \mathrm{cm}^{2}$, the process was much faster (about 15 min for the complete reduction),
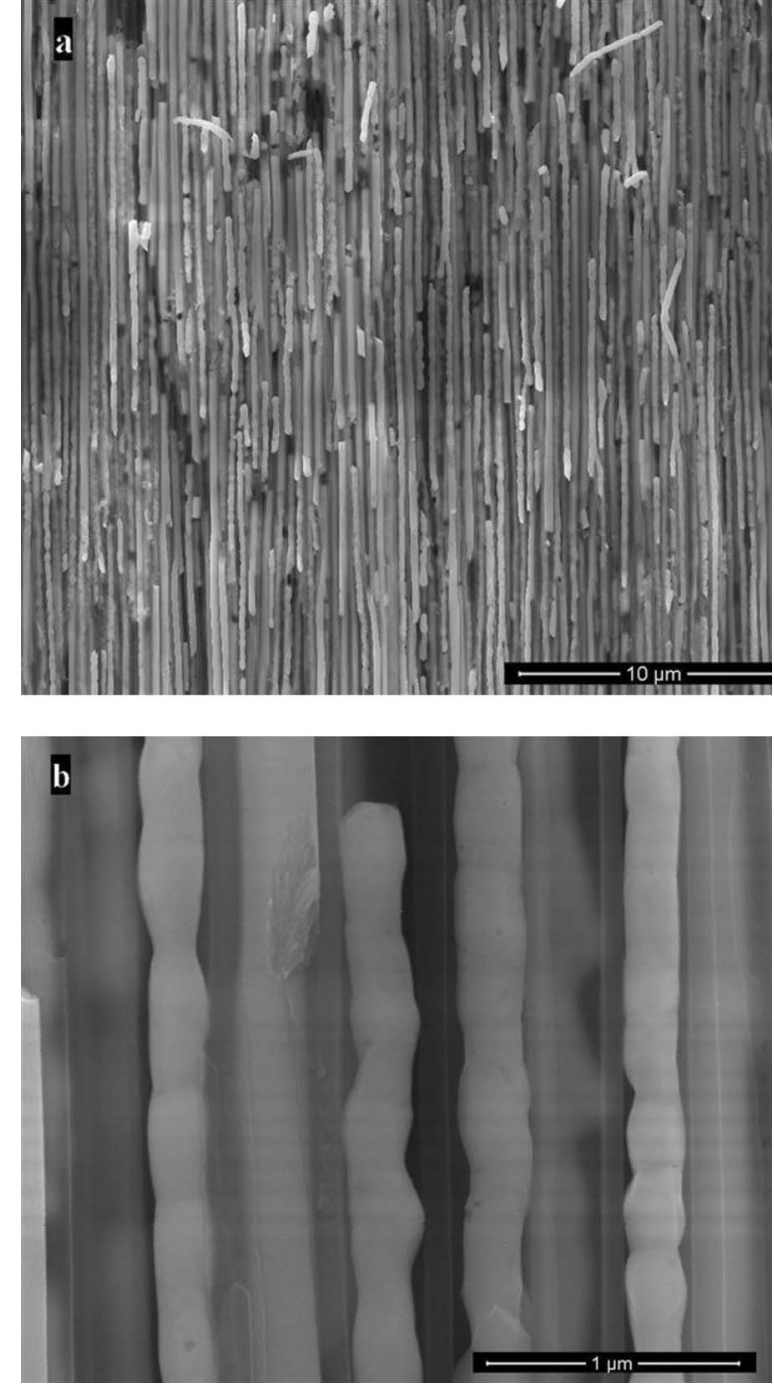

Figure 3. Cross-sectional views of $\mathrm{Pb} \mathrm{NW}$ into the $\mathrm{AAM}$ template obtained by amperostatic reduction of $\mathrm{PbO}_{2} \mathrm{NWs}$ at $10 \mathrm{~mA} / \mathrm{cm}^{2}$.

but the electrode potential decreased continuously toward more negative values. However, in these last cases, either membrane rupture or heavy damage was more frequent.

During the potentiostatic reduction (at $-1 \mathrm{~V} / \mathrm{SCE}$ ), the current always remained cathodic with quite high values $\left(50 \mathrm{~mA} / \mathrm{cm}^{2}\right.$ or more). At the end of the reduction process, the AAM template was damaged and fragile.

After the reduction process was complete, our template was uniformly filled with metallic $\mathrm{Pb}$ wires, as shown in the SEM micrographs in Fig. 3a and b. All pores were completely filled along the overall length. In Fig. 3b, the characteristic shape of lead NWs is evidenced: The diameter of each wire is not perfectly constant, but it oscillates, owing to the volume shrinkage following the oxide reduction process, giving an original "sausagelike" profile. Figure 4 displays the XRD patterns of the same sample, revealing the polycrystalline structure of the metal wires and the absence of any peak relative to $\mathrm{PbO}_{2}$. The complete conversion of $\mathrm{PbO}_{2}$ to metallic $\mathrm{Pb}$ along the entire NW length was confirmed both by XRD performed on the bottom side of the template (showing the presence of only $\mathrm{Pb}$ and Au peaks) and by the EDS analysis performed on the cross section of the template (showing no presence of $\mathrm{O}$ ). The same structural and morphological features were observed regardless of the reduction method (either galvanostatic or potentiostatic).

In conclusion, this indirect deposition method resulted in the 


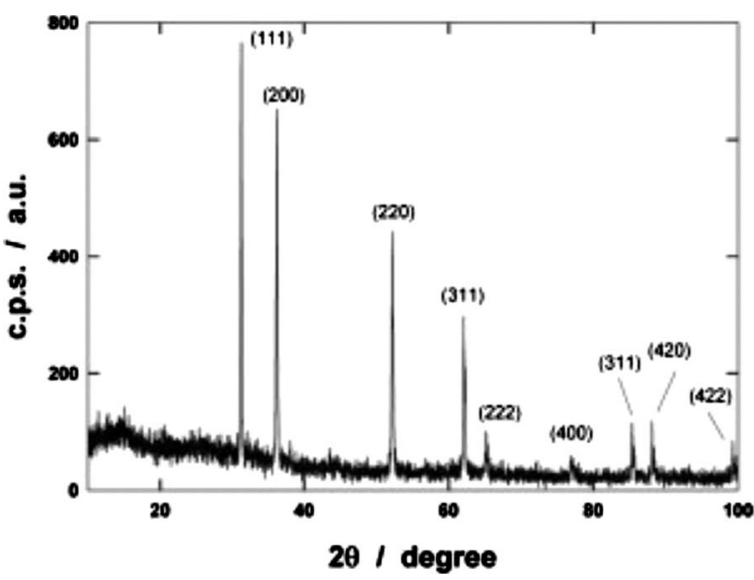

Figure 4. XRD patterns of the sample in Fig. 3.

complete and uniform filling of the AAM template with pure polycrystalline metallic lead. Compared with the long times of electrodeposition reported in Ref. 17-19, this procedure appears much faster.

However, a certain damage of the membrane was unavoidable when reduction was performed in a sulfuric acid solution. To prevent this effect, few preliminary experiments of reduction in a $1 \mathrm{M}$ $\mathrm{Na}_{2} \mathrm{SO}_{4}$ solution having the $\mathrm{pH}$ adjusted to 4 were done. A complete oxide reduction was achieved in galvanostatic runs at $5 \mathrm{~mA} \mathrm{~cm}$. Different from the previous case, no damage of the AAM template was observed, while metallic NW characterization gave the same results reported in Fig. 3 and 4.

\section{Conclusion}

With the final goal of building lead acid microbatteries, different methods of deposition of metallic lead NW arrays within pores of AAM templates were investigated.

Direct electrodeposition carried out potentiostatically and galvanostatically in slightly acidic electrolytes containing boric acid as a chelating agent, gave unsatisfactory results for the nonuniform template pore filling and NW length as well as for the slow deposition kinetics.

An indirect deposition procedure was then adopted, giving a complete and uniform filling of the AAM template with pure polycrystalline metallic lead, as confirmed by the morphological SEM analysis and by the XRD patterns.

This indirect deposition consists of two separate steps, both lasting a limited time. The first step is the deposition of $\alpha-\mathrm{PbO}_{2} \mathrm{NWs}$ into template pores at $+1.5 \mathrm{~V}$ (SCE) from a stirred solution of 0.2 $\mathrm{M}$ lead acetate at $T=60^{\circ} \mathrm{C}$ according to the method used in Ref. 6; after less than half an hour, the pores were completely filled with oxide NWs. The second step is the complete cathodic reduction of oxide NWs to metallic lead; also, this process was carried out successfully both in galvanostatic and potentiostatic modes. As for the electrolyte of choice for the reduction process, first attempts were carried out in a $5 \mathrm{M} \mathrm{H}_{2} \mathrm{SO}_{4}$ solution; however, because certain template damages are unavoidable in such an electrolyte, further experiments were performed in a slightly acidic $\mathrm{Na}_{2} \mathrm{SO}_{4}$ solution, and they gave positive results.

University of Palermo assisted in meeting the publication costs of this article.

\section{References}

1. R. W. Murray, Chem. Rev. (Washington, D.C.), 108, 2688 (2008).

2. E. Serrano, G. Rus, and J. Garcia-Martinez, Renewable Sustainable Energy Rev., 13, 2373 (2009).

3. G. G. Wallace, J. Chen, A. J. Mozer, M. Forsyth, D. R. MacFarlane, and C. Wang, Mater. Today, 12, 20 (2009).

4. A. J. Salkind, A. G. Cannone, and F. A. Trumbure, in Handbook of Batteries, D Linden and T. B. Reddy, Editors, p. 23, McGraw-Hill, New York (2002).

5. H. A. Kiehne, Battery Technology Handbook, Marcel Dekker, New York (2003).

6. R. Inguanta, S. Piazza, and C. Sunseri, J. Electrochem. Soc., 155, K205 (2008).

7. P. Perret, T. Brousse, D. Belanger, and D. Guay, J. Electrochem. Soc., 156, A645 (2009).

8. M. Jordan, in Modern Electroplating, M. Schlesinger and M. Paunivic, Editors, p. 361, John Wiley \& Sons, New York (2000).

9. A. T. Kuhn, The Electrochemistry of Lead, Academic, London (1979).

10. E. Ghali and M. Girgs, Metall. Trans. B, 16, 489 (1985).

11. A. López Valdivieso, J. L. Reyes Bahena, S. Songa, and R. Herrera Urbina, J. Colloid Interface Sci., 298, 1 (2006).

12. R. Inguanta, S. Piazza, and C. Sunseri, Nanotechnology, 18, 485605 (2007)

13. R. Inguanta, S. Piazza, and C. Sunseri, Electrochem. Commun., 11, 1385 (2009).

14. R. Inguanta, E. Rinaldo, S. Piazza, and C. Sunseri, Unpublished.

15. Power Diffraction File card no. 4-686 for metal $\mathrm{Pb}$ and no. $72-2440$ for $\alpha-\mathrm{PbO}_{2}$, International Centre for Diffraction Data, Philadelphia, PA.

16. Y.-S. Chi, Ph.D. Thesis, Graduate Institute of Chemistry, Academia Sinica, Taipei, Taiwan (2007).

17. Y.-T. Pang, G.-W. Meng, L.-D. Zhang, Y. Qin, X.-Y. Gao, A.-W. Zhao, and Q. Fang, Adv. Funct. Mater, 12, 719 (2002).

18. Y.-T. Pang, G.-W. Meng, L.-D. Zhang, W.-J. Shan, X.-Y. Gao, A.-W. Zhao, and Y.-Q. Mao, J. Phys.: Condens. Matter, 14, 11729 (2002)

19. X. Y. Zhang and J. Y. Dai, Nanotechnology, 15, 1166 (2004).

20. R. Inguanta, S. Piazza, and C. Sunseri, Appl. Surf. Sci., 255, 8816 (2009) 